\title{
Taguchi Orthogonal Array Dataset for the Effect of Water Chemistry on Aggregation of ZnO Nanoparticles
}

\author{
Rizwan Khan ${ }^{\mathbb{D}}$, Muhammad Ali Inam ${ }^{\mathbb{D}}$, Du Ri Park, Saba Zam Zam and Ick Tae Yeom * \\ Graduate School of Water Resources, Sungkyunkwan University (SKKU) 2066, Suwon 16419, Korea; \\ rizwankhan@skku.edu (R.K.); aliinam@skku.edu (M.A.I.); enfl8709@skku.edu (D.R.P.); \\ sabazamzam@skku.edu (S.Z.Z.) \\ * Correspondence: yeom@skku.edu; Tel.: +82-31-299-6699
}

Received: 29 May 2018; Accepted: 13 June 2018; Published: 15 June 2018

\begin{abstract}
The dynamic nature of engineered nanoparticle (ENP) aggregation behavior and kinetics are of paramount importance in the field of toxicological and environmental nanotechnology. The Taguchi orthogonal array $(\mathrm{OA}) \mathrm{L}_{27}\left(3^{13}\right)$ matrix based on a fractional factorials design was applied to systematically evaluate the contribution and significance of water chemistry parameters $(\mathrm{pH}$, temperature, electrolyte, natural organic matter (NOM), content and type) and their interactions in the aggregation behavior of zinc oxide nanoparticles (ZnO NPs). The NPs were dispersed into the solution using a probe-sonicator cell crusher (Bio-safer, 1200-90, Nanjing, China). The data were obtained from UV-Vis spectroscopy (Optizen 2120 UV, Mecasys, Daejeon, Korea), Fourier Transform Infrared Spectrometery (FT-IR 4700, spectroscopy, a JASCO Analytical Instruments, Easton, Pennsylvania, USA) and particle electrophoresis (NanoZS, Zetasizer, Malvern Instruments Ltd., Worcestershire, UK). The dataset revealed that Taguchi OA matrix is an efficient approach to study the main and interactive effects of environmental parameters on the aggregation of ZnO NPs. In addition, the aggregation profile of $\mathrm{ZnO}$ NPs was significantly influenced by divalent cations and NOM. The result of the FT-IR data presents a possible mechanism of ZnO NP stabilization in the presence of different NOM. This data may be helpful to predict the aggregation behavior of ZnO NPs in environmental and ecotoxicological contexts.
\end{abstract}

Dataset: Available as the supplementary file.

Dataset License: CC-BY

Keywords: aggregation; Fourier transform infrared spectrometer; Taguchi orthogonal array; UV-Vis spectrophotometer; water chemistry; zinc oxide nanoparticles

\section{Summary}

With the development of nanotechnology, production, and utilization of engineered nanoparticles (ENPs) has increased in consumer products and commercial applications. Among the diverse ENPs, zinc oxide nanoparticles (ZnO NPs) are the third most frequently used metal-containing nanomaterials due to their unique structural properties [1]. The estimated annual global production is currently between 570-33,400 t/year, and is anticipated to reach 58,000 t/year by 2020 [2]. However, such broad applications and production of ZnO NPs have generated concern to both the scientific and public communities due to their environmental release, which may increase the bioavailability and NPs' toxicity in an aqueous environment [3]. The potential adverse effects of ZnO NPs on phytoplankton, plants, and even human cell lines are well-known [4]. However, limited knowledge is available 
regarding the nanoparticle-liquid interaction and aggregation among NPs. Thus, understanding the aggregation phenomena of $\mathrm{ZnO} N P s$ under various parameters of water chemistry is important to properly assess their risk.

Several researchers have studied the $\mathrm{ZnO} N \mathrm{NP}$ fate and mobility in an aqueous environment [5-7]. ZnO NP aggregation phenomena are highly influenced by physicochemical properties and solution chemistry [8]. NP properties such as size, shape, and coating may cause substantial variation in their aggregation kinetics [9]. Few studies [10,11] have reported that large size particles tend to aggregate, however, tiny size particles remain suspended in solution and increase the risk of harm to aquatic species. The variation in solution $\mathrm{pH}$ and temperature affect the surface potential and solubility of $\mathrm{ZnO}$ NPs which may also influence their agglomeration phenomena [7,12]. Fast aggregation has been reported in high-salt content solutions due to compression of the electrical double layer (EDL) $[9,13]$. The studies also showed that ubiquitous natural organic matter (NOM) stabilizers kept $\mathrm{ZnO}$ NPs suspended in water due to steric hindrance and potential charge reversal $[14,15]$. Furthermore, few studies have demonstrated that the presence of divalent cations i.e., $\mathrm{Ca}^{2+}, \mathrm{Mg}^{2+}$ may form intermolecular bridging between NOM and $\mathrm{ZnO} N P s$, to promote aggregation [16]. Additionally, the presence of trivalent electrolytes such as aluminum sulfate ( $\mathrm{Al} 2(\mathrm{SO} 4) 3)$ with the strong potential to form a bridge between metal NPs and aggregates, may enhance the hetero-aggregation due to the formation of aluminum complexes [17,18]. These results further suggest that different electrolytes play a significant role in the aggregation of ENPs in aqueous matrices.

In previous studies [19-22], the influence of various environmental parameters on agglomeration phenomena of $\mathrm{ZnO}$ NPs has generally been studied using individual factors and has been limited to pure water. Additionally, the interaction of multiple parameters affecting this phenomenon has been rarely investigated by environmental scholars. Therefore, it is important to evaluate the aggregation phenomena of $\mathrm{ZnO}$ NPs together with a combination of different parameters that may affect their function and toxicity in an ecosystem.

A recent study has shown a significant influence of several environmental parameters on sedimentation and aggregation of ZnO NPs [23]. Numerous datasets on such phenomena of other ENPs i.e., copper oxide $(\mathrm{CuO})$ and titanium dioxide $\left(\mathrm{TiO}_{2}\right)$ have been reported [22,24]. However, to the knowledge of the authors, there are no datasets available regarding the effect of combined multiple environmental parameters on $\mathrm{ZnO} N \mathrm{NP}$ aggregation. In light of this, $\mathrm{ZnO} \mathrm{NP}$ aggregation phenomena in single and multiple environmental parameters were investigated. The fractional factorial method based on Taguchi orthogonal array $(\mathrm{OA}) \mathrm{L}_{27}\left(3^{13}\right)$ design matrix was used to measure the main and interactive effects of multiple factors. This study quantitatively presents a $\mathrm{ZnO}$ NPs aggregation dataset obtained from UV-Vis spectrophotometry, Fourier transform infrared spectrometry (FT-IR), zeta potential analysis and Optizen view 4.2.5 PC interference software.

The dataset obtained from the UV/Vis spectrophotometer presents the absorbance data of $\mathrm{ZnO}$ $\mathrm{NPs}$ at various environmental conditions such as $\mathrm{pH}$, electrolyte type and concentration, and NOM type and concentration. Earlier, the zeta potential and FT-IR spectra of ZnO-NOM complexes were elucidated under different aqueous matrices [23]. This data may contribute to a better understanding of the agglomeration phenomena and fate of $\mathrm{ZnO}$ NPs in complex heterogeneous environments.

\section{Data Description}

Here, we present a dataset of $\mathrm{ZnO} N P$ aggregation efficiency and its kinetics in an Excel (Microsoft Corp., Redmond, WA, USA) spreadsheet file (see supplementary material). Tables S1-S12 show the $\mathrm{ZnO}$ NP data obtained after a bench scale aggregation experiment which are listed and described in Tables 1 and 2 at $25^{\circ} \mathrm{C} \pm 0.5$. Tables S1 and S2 show the absorbance data across various wavelengths and concentrations. This data is used to determine the concentration from a quantitative standard linear curve based on the Beer-Lambert law. Table S3 shows turbidity data at various time and power levels of sonicator to obtain the optimum sonication condition for further aggregation experiments. The data in Table S4 contains the residual absorbance and zeta potential at various $\mathrm{pH}$ ranges. This data shows 
that the solubility of $\mathrm{ZnO} N \mathrm{~N}$ s increases sharply at $\mathrm{pH}$ below 7 or above 11 . Considering the dissolution of $\mathrm{ZnO} N P s$ at such conditions, further experiments were conducted in the $\mathrm{pH}$ range 7-9.5 to minimize this effect and to obtain systematic data of ZnO NP aggregation. The data in Tables S5 and S6 shows the residual absorbances and corresponding zeta potentials at various electrolytes, NOM types and concentrations after $6 \mathrm{~h}$. This can be used to predict the effect of interfering ions on the aggregation phenomena of ZnO NPs in an aqueous environment. Table S7 shows the time-resolved optical absorbance measured at $370 \mathrm{~nm}$ across various solution matrices. The aggregation rate $\mathrm{k}$ can be estimated from this data using Stokes sedimentation theory; it also indicates that aggregation kinetics may vary substantially in the presence of high electrolyte and NOM concentrations. Table S8 shows the data derived from FT/IR spectra of pristine ZnO NPs before and after interaction with high concentration of various NOM i.e., humic acid, salicylic acid and citric acid. It shows the percent transmittance against the wave numbers $\left(500-4000 \mathrm{~cm}^{-1}\right)$. This data is helpful in providing the information about modification in the surface of $\mathrm{ZnO}$ NPs after interaction with NOM.

Table 1. Type of experiment and condition of single parameter experiments.

\begin{tabular}{cccc}
\hline Experiment & Parameter & Unit & Condition \\
\hline $\mathrm{A}$ & $\mathrm{pH}$ & - & 3 to 12 \\
$\mathrm{~B}$ & $\mathrm{KCl}, \mathrm{Na}_{2} \mathrm{SO}_{4}$ & $\mathrm{mM}$ & 0.01 to 100 \\
$\mathrm{C}$ & $\mathrm{MgCl}_{2}$ & $\mathrm{mM}$ & 0.01 to 25 \\
$\mathrm{D}$ & $\mathrm{HA}, \mathrm{SA}, \mathrm{CA}$ & $\mathrm{mg} \cdot \mathrm{L}^{-1}$ & 0.5 to 100 \\
\hline
\end{tabular}

Where HA, SA and CA corresponds to humic acid, salicylic acid and citric acid respectively.

Table 2. The input parameter and their corresponding levels for the Taguchi $\mathrm{L}_{27}\left(3^{13}\right)$ experiment.

\begin{tabular}{ccccc}
\hline Parameter & Units & \multicolumn{3}{c}{ Level } \\
\hline & & 1 & 2 & 3 \\
$\mathrm{pH}$ & - & 7.0 & 8.0 & 9.5 \\
Electrolyte Concentration & $\mathrm{mM}$ & 25 & 50 & 100 \\
NOM Concentration ${ }^{*}$ & $\mathrm{mgL}^{-1}$ & 5 & 10 & 25 \\
Electrolyte type & - & $\mathrm{KCl}$ & $\mathrm{Na}_{2} \mathrm{SO}_{4}$ & $\mathrm{MgCl}_{2}$ \\
NOM type & - & $\mathrm{HA}$ & $\mathrm{SA}^{\circ}$ & $\mathrm{CA}$ \\
Temperature & ${ }^{\circ} \mathrm{C}$ & 15 & 25 & 35 \\
\hline & $*$ NOM corresponds to natural organic matter.
\end{tabular}

Furthermore, Tables S9-S11 show the data of residual absorbance and corresponding aggregation efficiencies, variance and range analysis obtained from Taguchi $\mathrm{OA} \mathrm{L}_{27}\left(3^{13}\right)$ matrix for multi-parameters experiments. This data is important to determine the analysis of variance (ANOVA) and, consequently, the dominant parameters influencing the ZnO NPs aggregation in a real environment. In addition, the data in Tables S12 and S13 shows the residual absorbance and aggregation efficiencies obtained across various environmentally tested waters. This data is helpful in providing $\mathrm{ZnO} \mathrm{NPs}$ aggregation phenomena in real environmental conditions.

\section{Methods}

\subsection{Solution and Synthetic Waters Preparation}

The nanopowder of ZnO NPs assay 97\%; humic acid sodium salt (HA), salicylic acid (SA) and citric acid (CA) were purchased from the Sigma-Aldrich (St. Louis, MO, USA) and used without further purification. While inorganic salts i.e., potassium chloride $(\mathrm{KCl})$, sodium sulfate $\left(\mathrm{Na}_{2} \mathrm{SO}_{4}\right)$, magnesium chloride $\left(\mathrm{MgCl}_{2} \cdot 6 \mathrm{H}_{2} \mathrm{O}\right)$, nitric acid $\left(\mathrm{HNO}_{3}\right)$, hydrochloric acid $(\mathrm{HCl})$, sodium hydroxide $(\mathrm{NaOH})$ used in this study were obtained from local suppliers. According to the vendor, NPs have particle size $<50 \mathrm{~nm}$ with a specific surface area $15-25 \mathrm{~m}^{2} / \mathrm{g}$ and it contain $6 \% \mathrm{Al}$ as dopant. The $100 \mathrm{mg} / \mathrm{L}$ of $\mathrm{ZnO}$ NPs solution was prepared by adding $10 \mathrm{mg}$ of $\mathrm{ZnO}$ nanopowder in $100 \mathrm{~mL}$ of nanopure 
water. The solution was subjected to probe-sonication using an ultrasonicator (ultrasonic cell crusher, Bio-safer, 1200-90, Nanjing, China) for 5-40 min and 100-600 W power to obtain a homogenous NP dispersion. Moreover, the solution turbidity was also measured using Turbidimeter (Hach Benchtop $2100 \mathrm{~N}$, Loveland, CO, USA). The natural organic matter (NOM) stock solutions were prepared by dissolving $1 \mathrm{~g}$ powder of each NOM in $1 \mathrm{~L}$ of deionized (DI) water. The $\mathrm{pH}$ of HA was adjusted to 10 using $\mathrm{NaOH}$ to ensure complete dissolution of HA. The solution was stirred at $600 \mathrm{rpm}$ for overnight to improve further stability [25]. All the stock solutions' $\mathrm{pH}$ values were adjusted to 7 prior to storage in the dark at $4{ }^{\circ} \mathrm{C}$. The stock solutions of inorganic salts with $0.1 \mathrm{M}$ ionic strength (IS) were prepared by adding $7.45 \mathrm{~g} \mathrm{KCl}, 14.2 \mathrm{~g} \mathrm{Na}_{2} \mathrm{SO}_{4}$ and $20.32 \mathrm{~g} \mathrm{MgCl}_{2} \cdot 6 \mathrm{H} 2 \mathrm{O}$ in $1 \mathrm{~L}$ solution respectively. Four synthetic waters were prepared in the laboratory, while tap water and wastewater were collected from Sungkyunkwan University, Suwon and metal processing industry located at Ulsan, Korea respectively. The detailed characteristics of all water samples are already presented in our previous study [23]. The IS (Ie) was calculated from the electrical conductively $(E C)$ [26] according to the following equation.

$$
I e=0.01442 \times E C^{1.009}
$$

\subsection{Standard Calibration Curve Analysis}

Prior to the aggregation experiments, optical absorption analysis was conducted using a UV/Vis spectrophotometer (Optizen 2120 UV, Mecasys, Daejeon, Korea) using a $100 \mathrm{~mm}$ path length quartz cuvette. The device was equipped with high-quality Tungsten-Halogen lamp and a Deuterium lamp which allows the analysis of ZnO NPs at relatively low concentrations (100 to $1000 \mu \mathrm{g} / \mathrm{L}$ ). The absorption spectra of the colloids were collected between $200-800 \mathrm{~nm}$ at $25{ }^{\circ} \mathrm{C}$. The background was set up with the proper solvent and then, each colloid sample was examined. Since UV-Vis spectra fit well to Beer-Lamber law; thus, a standard calibration curve was collected at $370 \mathrm{~nm}$ and used as a quantitative criterion of $\mathrm{ZnO} \mathrm{NPs}$.

\subsection{Aggregation Efficiency of Nanoparticles}

The $\mathrm{ZnO}$ NPs concentration and aggregation efficiencies were estimated using fitted curve equation having $\mathrm{R}^{2}$ of 0.9993 as shown in Equations (2) and (3). In current study, initial concentration of $\mathrm{ZnO}$ NPs in vial was maintained at $100 \mathrm{mg} / \mathrm{L}$.

$$
Y=0.0086 x-0.0116
$$

where $Y$ represents the concentration of ZnO NPs and $x$ indicates residual absorbance [24].

$$
A=\frac{C i-C t}{C i} \times 100
$$

where $A$ corresponds to aggregation efficiency, $\mathrm{C} i$ and $\mathrm{C} t$ are concentration of $\mathrm{ZnO}$ NPs before and after aggregation experiments.

\subsection{Aggregation and Sedimentation Experiments}

The experiments were conducted in standard sedimentation glass tubes (Fisher Scientific Co., Fair Lawn, NJ, USA) with the dimensions (height; $30 \mathrm{~cm}$, radius; $2 \mathrm{~cm}$ ) for $6 \mathrm{~h}$. The predetermined concentration of inorganic salts and NOM were spiked into $100 \mathrm{mg} / \mathrm{L}$ of ZnO NPs suspension. The $\mathrm{pH}$ was adjusted using $0.1 \mathrm{M} \mathrm{HCl}$ and $0.1 \mathrm{M} \mathrm{NaOH}$ solution. The suspension was subjected to ultrasonication to fully disperse the NPs in solution. However, in the case of NOM interactions, the $\mathrm{ZnO}$ NPs dispersions were ultrasonicated twice for a cycle of $15 \mathrm{~min}$. During the interval of two sonications, NOM was added and mixed with a magnetic stirrer for 5 min to homogenize the dispersion and then experiments were performed. After completion of aggregation experiments, $1 \mathrm{~mL}$ aliquots were collected from each suspension tube at $\frac{1}{4}$ height $(7.5 \mathrm{~cm}$ from top of tube) to measure 
the absorbance of residual ZnO NPs. Prior to aliquot analysis, the equipment was calibrated using a blank nanopure water solution. Following this approach, single- and multiple-parameter experiments were performed as shown in Tables 1 and 2. In the case of kinetic experiments, the instrument was specifically tuned in UV/Vis kinetic mode to optimize the wavelength at $370 \mathrm{~nm}$ and time setting in the selection window. Afterwards, the sample was placed in a quartz cuvette and the absorbance was continuously measured after every $3 \mathrm{~min}$. The settling rate and velocity of the NPs were calculated using first-order kinetics and Stokes's equation [27] respectively.

$$
\ln C t=\ln C i-k t
$$

where $t$ represents the time; $C_{i}$ and $C t$ are $\mathrm{ZnO}$ NPs concentrations at initial and time points, respectively; and $k$ is the sedimentation rate constant in $\left(\mathrm{h}^{-1}\right)$. Moreover, the settling velocity $V_{t}$ of

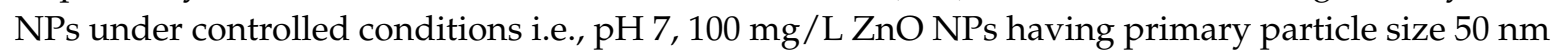
and density $5.60 \mathrm{~g} / \mathrm{cm}^{3}$ at various temperature levels $\left(15-35^{\circ} \mathrm{C}\right)$ were calculated using Stoke's law equation (Table 3).

$$
V_{t}=\frac{g d^{2}\left(\rho_{\rho}-\rho_{m}\right)}{18 \mu}
$$

where $g$ represents acceleration of gravity $\left(\mathrm{m} / \mathrm{s}^{2}\right), d$ particle diameter $(\mathrm{m}), \rho_{\rho}$ density of particle $\left(\mathrm{g} / \mathrm{cm}^{3}\right), \rho_{m}$ density of medium $\left(\mathrm{g} / \mathrm{cm}^{3}\right), \mu$ viscosity of medium $(\mathrm{g} / \mathrm{m} \cdot \mathrm{s})$ and $V_{t}$ settling velocity of particles respectively.

Table 3. Calculated Vt of ZnO NPs at various water temperature under controlled conditions.

\begin{tabular}{cccc}
\hline Temperature $\left({ }^{\circ} \mathrm{C}\right)$ & $\mathbf{1 5}$ & $\mathbf{2 5}$ & $\mathbf{3 5}$ \\
\hline $\mathrm{V}_{\mathrm{t}}\left(\times 10^{-3} \mathrm{~cm} / \mathrm{h}\right)$ & 1.978 & 2.533 & 3.105 \\
\hline
\end{tabular}

\subsection{Sample Preparation for FTIR Measurement}

The Fourier transform infrared spectra (FT/IR-4700, spectroscopy, JASCO Analytical Instruments, Easton, PA, USA) of ZnO NPs before and after interaction with various NOM were recorded. Spectroscopy has been used as a useful tool for the identification of structures and functional groups. The extracted aliquots of $\mathrm{ZnO}$ NOM complexes after aggregation experiment were collected and NPs were separated by centrifugation (Hettich Centrifuger Universal 320R, Tuttlingen, Germany) at 3000 RPM for $15 \mathrm{~min}$. The resultant ZnO NP pellets were subjected to vacuum drying for $24 \mathrm{~h}$ to remove any moisture content. The high sensitive Mercury-Cadmium-Telluride (MCT) focal-plane array detector was cooled for $30 \mathrm{~min}$ with liquid nitrogen (LIN). The dried samples were inserted into the sample platform to characterize the attachment of functional groups in the range of wave number 500-4000 $\mathrm{cm}^{-1}$. The Thermo Scientific OMNIC FTIR software was used to analyze the data and exported in the text file format for further processing.

\subsection{Zeta Potential Analysis}

After the aggregation experiments, an aliquot was removed from the suspension and placed into the zeta potential cell. The cell was filled up with the colloids avoiding the formation of bubbles. The electrophoretic mobility of the particles was measured using a Zetasizer Nano-ZS (Malvern Instrument Ltd., Worcestershire, UK). The temperature in the Zetasizer was set to $25 \pm 0.1^{\circ} \mathrm{C}$. Three electrophoretic mobility measurements were made for each sample. The value of electrophoretic mobility was directly converted by default function of equipment. The default Smoluchowski equation is given [28] below.

$$
\zeta=4 \pi \eta\left(\frac{V}{E}\right) / \varepsilon
$$


where $\zeta$ represents zeta potential $(\mathrm{mV}),\left(\frac{V}{E}\right)$ electrophoretic mobility $($ microns $/ \mathrm{sec} \times \mathrm{volt} / \mathrm{cm}), \eta$ solvent viscosity (poise) and $\varepsilon$ is dielectric constant.

\subsection{Characterization of Water Samples}

The aliquot obtained from tap and industrial wastewater were filtered through a $0.45-\mu \mathrm{m}$ glass fiber filter; digested with $99 \%$ pure $\mathrm{HNO} 3$ prior to analysis [29]. The Inductively coupled plasma mass spectrometry (ICP-MS, 7700x, Agilent Technologies, Palo Alto, CA, USA) was used to analyze the concentration of common element i.e., potassium $\left(\mathrm{K}^{+}\right)$, sodium $\left(\mathrm{Na}^{+}\right)$, copper $\left(\mathrm{Cu}^{2+}\right)$, iron $(\mathrm{Fe})$, magnesium $\left(\mathrm{Mg}^{2+}\right)$, arsenic $(\mathrm{As})$, calcium $\left(\mathrm{Ca}^{2+}\right)$ and antimony $(\mathrm{Sb})$. The industrial wastewater filtered samples were further diluted in 1:10 ratio to measure the concentration of common anions $\left(\mathrm{NO}_{3}{ }^{-}, \mathrm{Cl}^{-}\right.$ and $\mathrm{SO}_{4}{ }^{2-}$ ) using ion chromatography with metrosep A Supp5 column in (861 Advanced Compact IC, Metrohm, Herisau, Switzerland).

\subsection{Taguchi Orthogonal Array Experimental Design}

In recent years, many design of experiments (DOE) including full factorial and fractional factorial design have been developed and widely used in many engineering fields to optimize and design experiments [30-32]. A full factorial design may become onerous to be completed with the increase of number of parameters. Therefore, the concept of Taguchi orthogonal array (OA) based on fractional factorial design was developed by Dr. Genichi Taguchi to study a large number of variables with a small number of experimental trials [33]. Using the OA approach significantly reduce the number of experimental configurations to be studied and provides the main and interactive effects. The parameters and levels are selected according to the experimental design. The term parameters correspond to the number of experimental variables while the term levels show the number of different values a variable can assume according to its discretization.

In the current study, the variation of all input parameters was systematically studied at three levels as shown in Table 2. We applied the standard OA $\mathrm{L}_{27}\left(3^{13}\right)$ (Figure 1a) of Taguchi method using various parameters of water chemistry to investigate $\mathrm{ZnO} N P$ aggregation behavior. The standard $\mathrm{OA}$ was modified (Figure $1 \mathrm{~b}$ ) using a line separation method to assign the parameters and interactions to various columns. The $\mathrm{ZnO}$ NPs aggregation phenomena were evaluated under the control of six parameters i.e., $\mathrm{pH}(\mathrm{A})$, electrolyte concentration (B), NOM concentration (C), electrolyte type (D), NOM type (E) and temperature (F) with three levels and two potential interactions i.e., $\mathrm{A} \times \mathrm{B}$ and $\mathrm{B} \times \mathrm{C}$. The $\mathrm{OA} \mathrm{L}_{27}\left(3^{13}\right)$ which has 27 rows corresponds to a number of trials with 13 columns at 3 levels as shown in Table S9. The plan of the experiment was as follows. The $\mathrm{pH}(\mathrm{A})$ was assigned in the first column, electrolyte concentration (B) in the second column, NOM concentration (C) in the fifth column, electrolyte type (D) in ninth column, NOM type (E) in tenth column and temperature (F) in the twelfth column. The possible two parameter interactions $(\mathrm{A} \times \mathrm{B})_{1}$ and $(\mathrm{A} \times \mathrm{B})_{2}$ were assigned to third and fourth columns while eighth and eleventh were assigned to $(B \times C)_{1}$ and $(B \times C)_{2}$ interactions. The remaining sixth, seventh and thirteenth columns were left empty in order to calibrate the standard matrix. The experiments were conducted for each combination of parameters as per selected OA in triplicate and average values were reported.
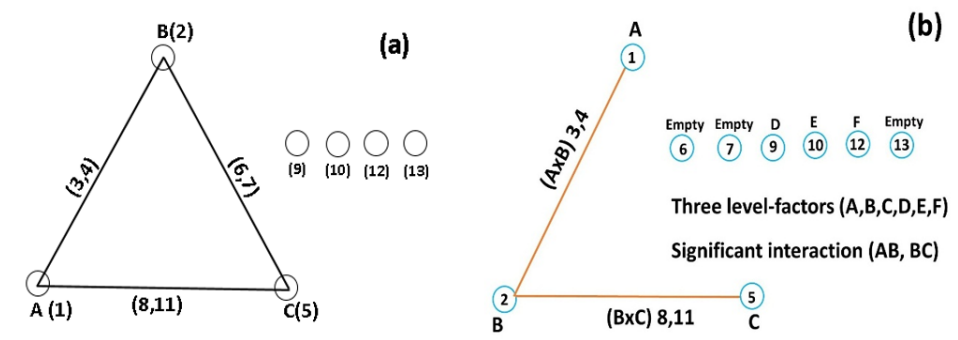

Figure 1. Standard linear graph for $\mathrm{L}_{27}\left(3^{13}\right)$ array $(\mathbf{a})$; and modified linear graph for column assignment (b). 


\subsection{Statistical Analysis}

The experimental data obtained by following the Taguchi OA matrix procedure were analyzed by the general linear model (GLM) with Tukey's post Hoc test using the software MINITAB18.0 (Minitab, Inc., State College, PA, USA). The MINITAB was also used for range analysis and analysis of variance (ANOVA) and predicting the dominant parameters for ZnO NPs aggregation. Probability p-value less than 0.05 were considered to be significant. The normality and homogeneity of data were considered before conducting the ANOVA. Each experiment was performed in triplicate and average values were reported.

\subsection{Optizen View 4.2.5}

A UV-Vis spectrophotometer was connected with a PC interference software "Optizen view 4.2.5" to obtain the absorbance and real-time kinetics data of ZnO NPs in solution. The method adopted for obtaining sample survey scans and kinetic data is illustrated in Figure 2a-d.

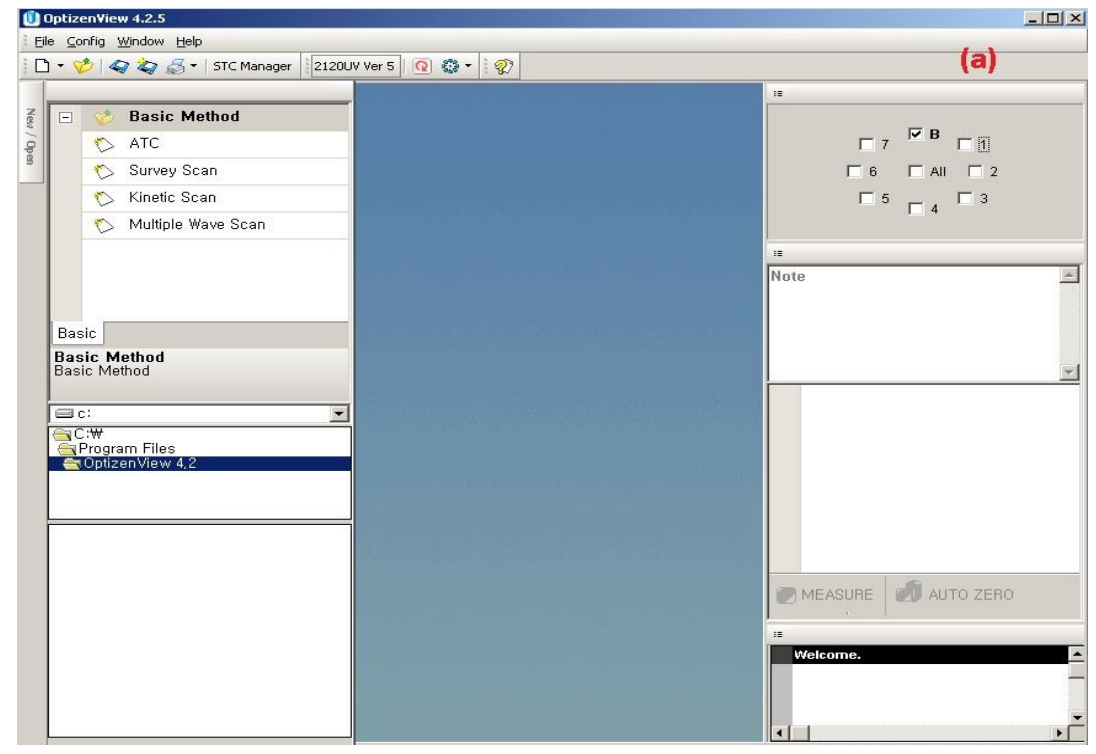

(a)

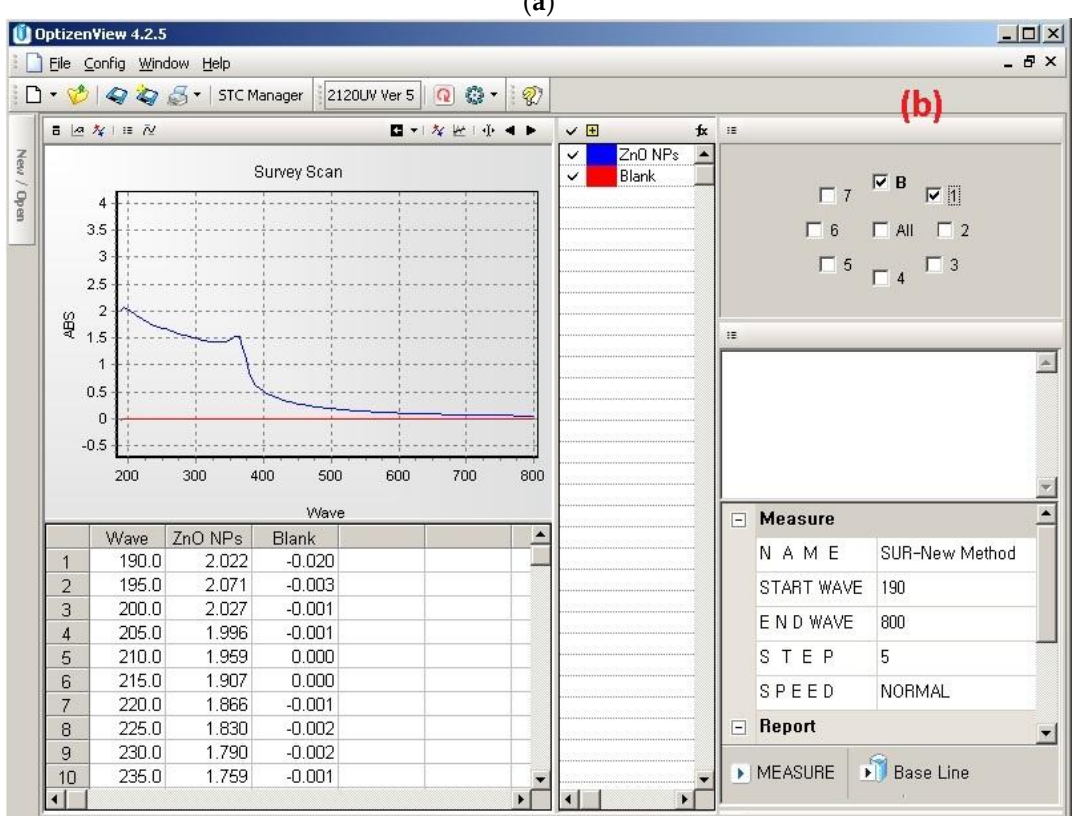

(b)

Figure 2. Cont. 


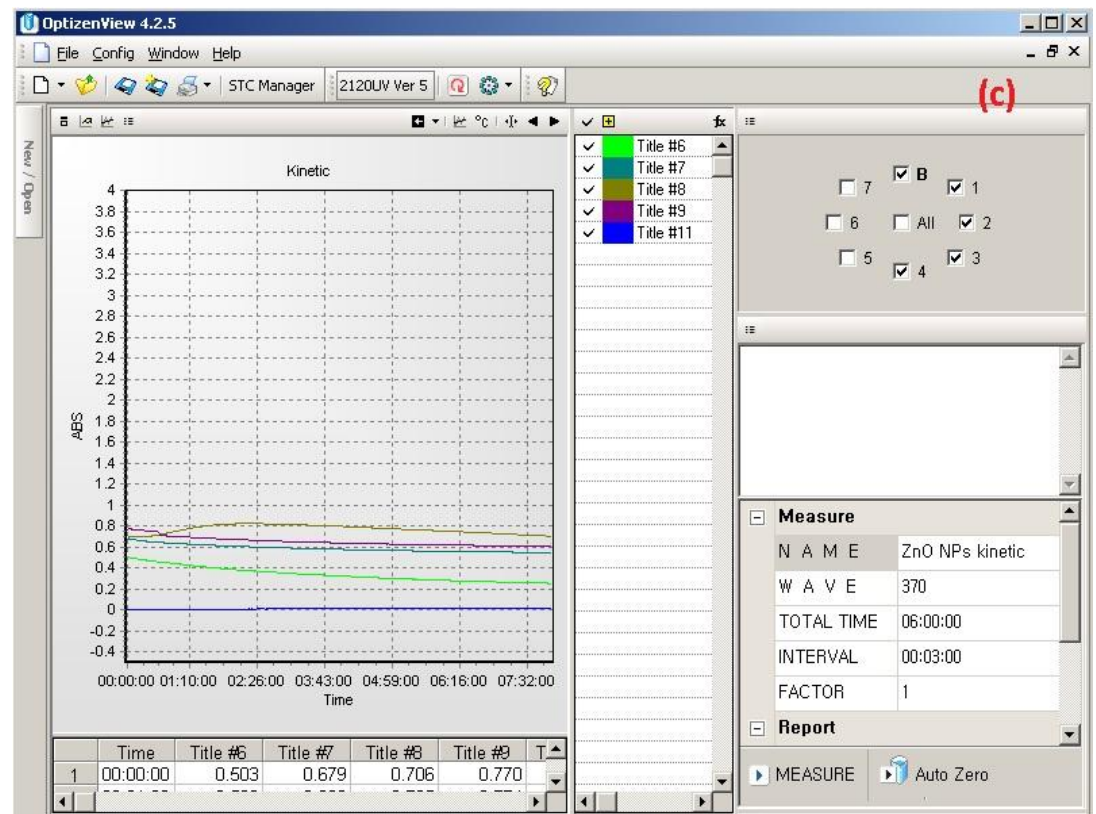

(c)

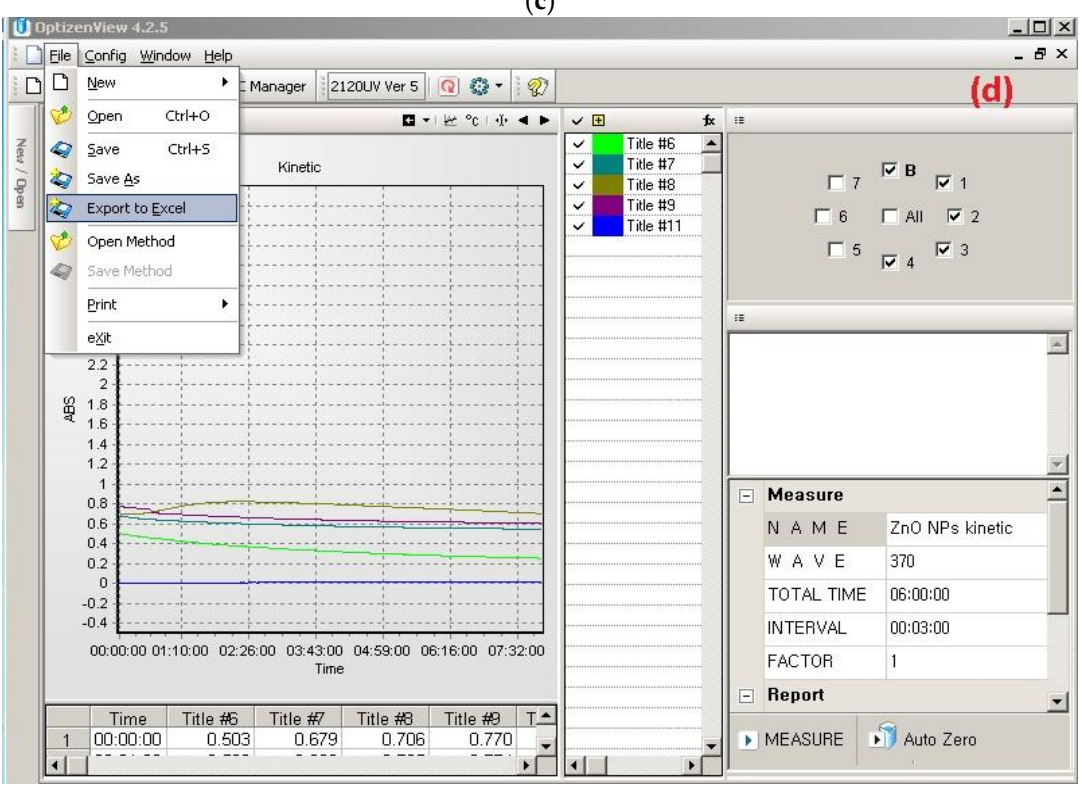

(d)

Figure 2. An illustration of Optizen view 4.2.5 software showing (a) main screen of user interference; (b) survey scan for determination of ZnO NPs wavelength; (c) time-resolved kinetic study of ZnO NPs under various solution chemistry; (d) procedure to export data to Excel.

\section{User Note}

Our dataset provides quality information about the sedimentation and aggregation phenomena of $\mathrm{ZnO}$ NPs that might be useful for researchers and the scientific community. The approach described here may help researchers who intend to increase the number of parameters and their interactions, in the range of our dataset. In addition, it may add to toxicological studies about ENPs, given that many parameters in our dataset are commonly found in natural water bodies. In the view of a global scale, one may use the dataset to incorporate more information of water chemistry parameters present in the local environments to assess other parameters that were not covered in the current matrix data.

Supplementary Materials: The following are available online at http:/ / www.mdpi.com/2306-5729/3/2/21/s1. Table S1: Survey scan of ZnO NPs suspension in nanopure water, Table S2: Standard linear Curve of ZnO 
NPs at $365 \mathrm{~nm}$, Table S3: Turbidity of the solution at various time and power levels of sonicator, Table S4: Absorbance and zeta potential of $\mathrm{ZnO}$ NPs at various $\mathrm{pH}$ range, Table S5: Absorbance of ZnO NPs at different electrolyte concentration of $\mathrm{KCl}, \mathrm{Na}_{2} \mathrm{SO}_{4}$ and $\mathrm{MgCl}_{2}$, Table S6: Absorbance and corresponding zeta potential of ZnO NPs at various NOM concentrations of humic, salicyclic and citric acid respectively, Table S7: Normalized absorbance of ZnO NPs at various experimental conditions, Table S8: FT-IR spectra of ZnO NPs before and after interaction with $100 \mathrm{mg} / \mathrm{L}$ concentration of various NOM, Table S9: Column assignment for various parameters and two interactions in Taguchi $\mathrm{L}_{27}\left(3^{13}\right)$ orthogonal array and experimental absorbance, Table S10: The detail of the range analysis, Table S11: The detail result of the variance analysis, Table S12: Aggregation kinetic of Environmental Water samples, Table S13: Characterization of various environmental water samples and corresponding residual absorbance.

Author Contributions: R.K. and I.T.Y. conceived and designed the study. R.K. and M.A.I. conducted the experiment. S.Z.Z. and D.R.P. were responsible for experimental setup arrangements. R.K. and M.A.I. analyzed and revised the dataset. R.K. led the writing of the manuscript.

Conflicts of Interest: The authors declare no conflict of interest.

\section{References}

1. Keller, A.A.; McFerran, S.; Lazareva, A.; Suh, S. Global life cycle releases of engineered nanomaterials. J. Nanopart. Res. 2013, 15. [CrossRef]

2. Handy, R.D.; Von Der Kammer, F.; Lead, J.R.; Hassellöv, M.; Owen, R.; Crane, M. The ecotoxicology and chemistry of manufactured nanoparticles. Ecotoxicology 2008, 17, 287-314. [CrossRef] [PubMed]

3. Xia, T.; Kovochich, M.; Liong, M.; Mädler, L.; Gilbert, B.; Shi, H.; Yeh, J.I.; Zink, J.I.; Nel, A.E. Comparison of the Mechanism of toxicity of Zinc and Cerium Oxide Nanoparticles Based on Dissolution and Oxidative Stress Properties. Am. Chem. Soc. Nano 2008, 2, 2121-2134. [CrossRef] [PubMed]

4. $\quad$ Brunner, T.J.; Wick, P.; Manser, P.; Spohn, P.; Grass, R.N.; Limbach, L.K.; Bruinink, A.; Stark, W.J. In vitro cytotoxicity of oxide nanoparticles: Comparison to asbestos, silica, and the effect of particle solubility. Environ. Sci. Technol. 2006, 40, 4374-4381. [CrossRef] [PubMed]

5. Majedi, S.M.; Kelly, B.C.; Lee, H.K. Combined effects of water temperature and chemistry on the environmental fate and behavior of nanosized zinc oxide. Sci. Total Environ. 2014, 496, 585-593. [CrossRef] [PubMed]

6. Baalousha, M. Aggregation and disaggregation of iron oxide nanoparticles: Influence of particle concentration, $\mathrm{pH}$ and natural organic matter. Sci. Total Environ. 2009, 407, 2093-2101. [CrossRef] [PubMed]

7. Zhang, Y.; Chen, Y.; Westerhoff, P.; Hristovski, K.; Crittenden, J.C. Stability of commercial metal oxide nanoparticles in water. Water Res. 2008, 42, 2204-2212. [CrossRef] [PubMed]

8. Degen, A.; Kosec, M. Effect of $\mathrm{pH}$ and impurities on the surface charge of zinc oxide in aqueous solution. J. Eur. Ceram. Soc. 2000, 20, 667-673. [CrossRef]

9. Zhou, D.; Keller, A.A. Role of morphology in the aggregation kinetics of ZnO nanoparticles. Water Res. 2010, 44, 2948-2956. [CrossRef] [PubMed]

10. Mudunkotuwa, I.A.; Rupasinghe, T.; Wu, C.-M.; Grassian, V.H. Dissolution of ZnO Nanoparticles at Circumneutral pH: A Study of Size Effects in the Presence and Absence of Citric Acid. Langmuir 2012, 28, 396-403. [CrossRef] [PubMed]

11. Liu, W.S.; Peng, Y.H.; Shiung, C.E.; Shih, Y.H. The effect of cations on the aggregation of commercial ZnO nanoparticle suspension. J. Nanopart. Res. 2012, 14. [CrossRef]

12. Bian, S.W.; Mudunkotuwa, I.A.; Rupasinghe, T.; Grassian, V.H. Aggregation and dissolution of $4 \mathrm{~nm} \mathrm{ZnO}$ nanoparticles in aqueous environments: Influence of $\mathrm{pH}$, ionic strength, size, and adsorption of humic acid. Langmuir 2011, 27, 6059-6068. [CrossRef] [PubMed]

13. Van Hoecke, K.; De Schamphelaere, K.A.C.; Van Der Meeren, P.; Smagghe, G.; Janssen, C.R. Aggregation and ecotoxicity of $\mathrm{CeO}_{2}$ nanoparticles in synthetic and natural waters with variable $\mathrm{pH}$, organic matter concentration and ionic strength. Environ. Pollut. 2011, 159, 970-976. [CrossRef] [PubMed]

14. Philippe, A.; Schaumann, G.E. Interactions of dissolved organic matter with natural and engineered inorganic colloids: A review. Environ. Sci. Technol. 2014, 48, 8946-8962. [CrossRef] [PubMed]

15. Zhu, M.; Wang, H.; Keller, A.A.; Wang, T.; Li, F. The effect of humic acid on the aggregation of titanium dioxide nanoparticles under different $\mathrm{pH}$ and ionic strengths. Sci. Total Environ. 2014, 487, 375-380. [CrossRef] [PubMed] 
16. Keller, A.A.; Wang, H.; Zhou, D.; Lenihan, H.S.; Cherr, G.; Cardinale, B.J.; Miller, R.; Zhaoxia, J.I. Stability and aggregation of metal oxide nanoparticles in natural aqueous matrices. Environ. Sci. Technol. 2010, 44, 1962-1967. [CrossRef] [PubMed]

17. Zhang, J.; Dong, Q.; Liu, Y.; Zhou, X.; Shi, H. Response to shock load of engineered nanoparticles in an activated sludge treatment system: Insight into microbial community succession. Chemosphere 2016, 144, 1837-1844. [CrossRef] [PubMed]

18. Zhou, X.; Huang, B.-C.; Zhou, T.; Liu, Y.C.; Shi, H. Aggregation behavior of engineered nanoparticles and their impact on activated sludge in wastewater treatment. Chemosphere 2015, 119, 568-576. [CrossRef] [PubMed]

19. Li, X.; Lenhart, J.J.; Walker, H.W. Aggregation kinetics and dissolution of coated silver nanoparticles. Langmuir 2012, 28, 1095-1104. [CrossRef] [PubMed]

20. Zhang, Y.; Chen, Y.; Westerhoff, P.; Crittenden, J. Impact of natural organic matter and divalent cations on the stability of aqueous nanoparticles. Water Res. 2009, 43, 4249-4257. [CrossRef] [PubMed]

21. Peng, Y.H.; Tsai, Y.C.; Hsiung, C.E.; Lin, Y.H.; hsin Shih, Y. Influence of water chemistry on the environmental behaviors of commercial $\mathrm{ZnO}$ nanoparticles in various water and wastewater samples. J. Hazard. Mater. 2017, 322, 348-356. [CrossRef] [PubMed]

22. Peng, C.; Shen, C.; Zheng, S.; Yang, W.; Hu, H.; Liu, J.; Shi, J. Transformation of CuO Nanoparticles in the Aquatic Environment: Influence of pH, Electrolytes and Natural Organic Matter. Nanomaterials 2017, 7. [CrossRef] [PubMed]

23. Khan, R.; Inam, M.A.; Zam, S.Z.; Park, D.R.; Yeom, I.T. Assessment of Key Environmental Factors Influencing the Sedimentation and Aggregation Behavior of Zinc Oxide Nanoparticles in Aquatic Environment. Water 2018, 10. [CrossRef]

24. He, G.; Chen, R.; Lu, S.; Jiang, C.; Liu, H.; Wang, C.; He, G.; Chen, R.; Lu, S.; Jiang, C.; et al. Dominating Role of Ionic Strength in the Sedimentation of $\mathrm{Nano}^{-\mathrm{TiO}_{2}}$ in Aquatic Environments. J. Nanomater. 2015, 2015, 1-10. [CrossRef]

25. Dong, Y.; Li, X.; Huang, Y.; Wang, H.; Li, F. Coagulation and dissolution of zinc oxide nanoparticles in the presence of humic acid under different pH values. Environ. Eng. Sci. 2016, 33, 347-353. [CrossRef]

26. Marion, G.M.; Babcock, K.L. Predicting specific conductance and salt concentration in dilute aqueous solutions. Soil Sci. 1976, 122, 181-187. [CrossRef]

27. Kato, H.; Fujita, K.; Horie, M.; Suzuki, M.; Nakamura, A.; Endoh, S.; Yoshida, Y.; Iwahashi, H.; Takahashi, K.; Kinugasa, S. Dispersion characteristics of various metal oxide secondary nanoparticles in culture medium for in vitro toxicology assessment. Toxicol. Vitr. 2010, 24, 1009-1018. [CrossRef] [PubMed]

28. Smoluchowski, M. Handbuch der Elektrizitat und Magnetisums 1914; Graetz, L., Ed.; Barth-Verlag: Leipzig, Germany, 1921.

29. Fang, L.; Xiao, X.; Kang, R.; Ren, Z.; Yu, H.; Pavlostathis, S.G.; Luo, J.; Luo, X. Highly Selective Adsorption of Antimonite by Novel Imprinted Polymer with Microdomain Confinement Effect. J. Chem. Eng. Data 2018, 63, 1513-1523. [CrossRef]

30. Phadke, M.S. Quality Engineering Using Robust Design; Prentice Hall: Upper Saddle River, NJ, USA, 1989; ISBN 0137451679.

31. Lan, W.G.; Wongt, M.K.; Chen, N.; Sin, Y.M. Orthogonal array design as a chemometric method for the optimization of analytical procedures. Part 5. Three-level design and its application in microwave dissolution of biological samples. Analyst 1995, 120, 1115-1124. [CrossRef] [PubMed]

32. Chidambara, R.; Quan, H.Q. Advanced oxidation processes for wastewater treatment: Optimization of $\mathrm{UV} / \mathrm{H} 2 \mathrm{O} 2$ process through a statistical technique. Chem. Eng. Sci. 2005, 60, 5305-5311. [CrossRef]

33. Taguchi, G.; Konishi, S.; Konishi, S. Taguchi Methods: Orthogonal Arrays and Linear Graphs: Tools for Quality Engineering; American Supplier Institute: Dearborn, MI, USA, 1987; ISBN 094124301X.

(C) 2018 by the authors. Licensee MDPI, Basel, Switzerland. This article is an open access article distributed under the terms and conditions of the Creative Commons Attribution (CC BY) license (http://creativecommons.org/licenses/by/4.0/). 